\title{
First Missiles, then Nukes? Explaining the Connection between Missile Programs and the Proliferation of Nuclear Weapons
}

\author{
Bryan Robert Early and Christopher Way
}

\begin{abstract}
If countries invest in acquiring missile technology, does that in turn raise their likelihood of obtaining nuclear weapons capabilities? We argue that states that make long-term investments in mastering rocket technology are more likely to become latent nuclear weapons states or acquire nuclear weapons. Investing in the development of scientific and military industrial complexes (SMICs) within the military rocketry sector provides positive spillover from the research infrastructure that is built, the industries and scientific communities that are cultivated, and the lessons derived from managing complex research endeavors. Furthermore, such programs create constituencies that will advocate for the acquisition of nuclear weapons. Via a global analysis from 1945 to 2007, we find that possessing mature military rocketry R\&D programs, as opposed to simply possessing short-range ballistic missiles (SRBMs), increases the likelihood that a country will acquire the capabilities to produce nuclear weapons. Our findings contribute to the research agendas on the domestic sources of security policy and supply-side theories of nuclear proliferation.
\end{abstract}

Key Words: nuclear weapons, missiles, rocketry, proliferation, international security, military industrial complex

$\mathrm{N}$ uclear weapons and ballistic missiles are two of the most important strategic weapons systems that countries can obtain, especially when those technologies are combined (Schelling 1966). For instance, the strategic threat posed by the Democratic People's Republic of Korea's (DPRK) ballistic missile

*Bryan R. Early(bearly@albany.edu) is an Associate Professor of Political Science and the Director of the Center for Policy Research at the SUNY at Albany. He is also the founding Director of the Project on International Security, Commerce, and Economic Statecraft (PISCES).

**Christopher Way(christopher.way@cornell.edu) is an Associate Professor of Government at Cornell University.

The authors would like to thank Victor Asal, Matthew Fuhrmann, Erik Gartzke, and David Rousseau and anonymous reviewers for their comments on previous versions. Replication materials are available at https://sites.google.com/site/bryanrearly/home/data-sets. 
program became much more dangerous once it acquired nuclear weapons. Similarly, the strategic value of Iran's ballistic missile arsenal would be dramatically enhanced if it possessed nuclear weapons with which to arm them. Despite the clear affinity between ballistic missiles and nuclear weapons, much remains unknown about the dynamics linking the proliferation of rocket and nuclear technologies. In this study, we explain how countries' missile programs can influence their ability and desire to acquire nuclear weapons.

Nuclear-armed ballistic missiles require the effective synthesis of both nuclear weapons technology and rocketry technology. Yet while all countries that obtain nuclear weapons have incentives to acquire long-range missiles capable of serving as delivery systems, ${ }^{1}$ a large number of states have only sought to acquire ballistic missiles without pursuing nuclear weapons (e.g. Greece, Yemen, Poland, and the United Arab Emirates). Although missile and nuclear capabilities can clearly complement one another, it is not immediately clear what causal mechanisms link the proliferation of missile and nuclear technologies.

We theorize that states' long-term investments in military rocketry research and development (R\&D) programs spur the growth of scientific-militaryindustrial complexes (SMICs) that enhance countries' scientific, technical, and organizational capabilities to acquire nuclear weapons technologies and strengthen the bureaucratic support for such efforts. Efforts to develop indigenous missile capabilities help states build up the scientific and technical infrastructure, human capital, and industrial base necessary for a nuclear weapons program. The positive spillover effects from developing rocketryrelated SMICs on states' nuclear programs can be indirect or direct, depending on how governments organize their R\&D efforts for the acquisition of both types of technologies. Secondly, efforts undertaken to acquire strategic missile capabilities can catalyze bureaucratic and political demands for the acquisition of complementary nuclear capabilities (Halperin 1974; Sagan 1996/1997), as well as demonstrate (if the missile programs are successful) the organizational capacity necessary to orchestrate large-scale, complex, and integrated scientific/ industrial projects. By virtue of these dynamics, we hypothesize that countries that possess mature military rocketry R\&D programs will be significantly advantaged in mastering nuclear weapons technologies and be more likely to acquire nuclear weapons. Contrasting this view, we present a rival argument that focuses on how the acquisition of ballistic missiles could increase states' demand-side incentives to obtain nuclear weapons as strategic complements

\footnotetext{
${ }^{1}$ For recent examples that consider the linkages between nuclear weapons and nuclear weapons delivery systems, see Gartzke, Kaplow, and Mehta (2014); Mettler and Reiter (2013).
} 
to their missile arsenals. Drawing on this perspective, it is hypothesized that the acquisition of short-range ballistic missiles (SRBMs) will increase states' likelihoods of acquiring nuclear weapons and/or their related technologies.

We conduct a quantitative analysis of the effects of states' military rocketry R \& D programs and ballistic missile arsenals on 168 countries' likelihoods of acquiring nuclear weapons (Signh and Way 2004) and achieving nuclear latency (Fuhrmann and Tkach 2015) from 1945 to 2007. Employing a variety of different analytical methods, we find consistent evidence that simply possessing SRBMs does not increase states' likelihoods of acquiring nuclear weapons or achieving nuclear latency but possessing a mature military rocketry R\&D programs does. These findings hold even when we control for a range of other security factors driving states to try to acquire nuclear weapons. Our argument also appears to shed specific light on the proliferation strategy pursued by the DPRK, which focused first on the development of missile capabilities before turning to the acquisition of nuclear weapons.

Our study has a number of implications for the literature on foreign policy and nonproliferation. Our theoretical explanation contributes to research efforts linking domestic politics to states' foreign and defense policies (Allison 1971; Halperin 1974; Sagan 1996/1997; Sebato 2010). Our findings show that the military's possession of a weapons system that is a strategic complement to nuclear weapons is not enough to drive nuclear weapons proliferation. Instead, we find that it is the possession of a more expansive military rocketry SMIC that can push policymakers towards acquiring nuclear weapons capabilities and facilitate their acquisition efforts. Our project also contributes to the wider literature on the proliferation of military technology in the international system (Brooks 2005; Horowitz 2010; Fuhrmann and Horowitz 2017). In particular, it contributes to recent work on how various weapons of mass destruction acquisition efforts can complement one another (Horowitz and Narang 2014). We also contribute to the research agenda on the supply-side dynamics affecting nuclear weapons proliferation (e.g. Singh and Way 2004; Jo and Gartzke 2007; Fuhrman 2009; 2012; Kroenig 2009b), by illustrating the importance of a previously unknown factor influencing whether states succeed in acquiring nuclear weapons. Beyond our study's academic contributions, it also has a number of potentially valuable insights for policymakers that we discuss in the conclusion.

Our study proceeds as follows. The next section situates our contribution within the literature on nuclear weapons proliferation. We then draw on this literature to develop an explanation of how countries' military rocketry R\&D programs contribute to their likelihood of obtaining nuclear weapons. Next, we 
present our research design and execute our quantitative analysis. We conclude with a discussion of our findings' theoretical and policy implications.

\section{EXPLANATIONS FOR NUCLEAR WEAPONS PROLIFERATION}

To situate our inquiry within the broader literature, we first weigh the prospective benefits and costs entailed by the pursuit and possible acquisition of nuclear weapons. Put differently, we can focus on the motives to proliferate (the demand side) and the constraints on proliferation (the supply side), which may be domestic, international, or technological. We then discuss how the acquisition of expertise in military rocketry technology affects these motives and constraints.

\section{MOTIVES FOR OBTAINING NUCLEAR WEAPONS}

First, different states will place different value on acquiring nuclear weapons. Enhancing state security is one obvious motive: possession of nuclear weapons may render a state less vulnerable to coercion and dissuade would-be attackers. Typical formulations emphasize securing the state's territorial integrity and sovereign interests, particularly when confronting a rival possessing superior conventional might. ${ }^{2}$ These motives may be particularly strong for leaders of unpopular regimes facing threats of regime change from foreign powers. It has been argued, for example, that smaller-sized pariah regimes, like the DPRK or Saddam Hussein's Iraq, might be able to deter stronger countries from interfering in their domestic affairs with the aid of even a small nuclear arsenal (Freedman 1994). ${ }^{3}$

Non-security motives may also fuel a state's pursuit of nuclear weapons (Sagan 1996/1997). Specific parts of the state apparatus - possibly including agencies focusing on scientific endeavors and part of the military - may promote the pursuit of nuclear weapons as part of a bureaucratic struggle for greater resources and prestige, and some industries may have parochial reasons to join them in this effort. ${ }^{4}$ In some cases, insulated strategic/scientific "enclaves" have been identified as key actors pushing nuclear weapons programs forward

\footnotetext{
${ }^{2}$ See Betts (1993); Singh and Way (2004); Jo and Gartzke (2007).

${ }^{3}$ Along those lines, Way and Weeks (2014) found that countries ruled by personalist dictators are more likely to pursue nuclear weapons than other states.

${ }^{4}$ For example, see Sagan (1996/1997) and Solingen (2007).
} 
(Perkovich 1999; Sagan 2000). In addition, leaders and populations might perceive nuclear weapons as a marker of technological prowess and modernity and attach prestige to becoming part of the elite "club" of nuclear weapons possessors (Sagan 1996/1997; O’Neill 2006).

\section{THE COSTS AND CHALLENGES INVOLVED IN OBTAINING NUCLEAR WEAPONS}

The substantial costs entailed by the pursuit of nuclear weapons need to be weighed against these benefits. First, developing and potentially deploying nuclear weapons is an expensive, technically challenging endeavor, especially for small and/or impoverished states. ${ }^{5}$ The opportunity costs of the nuclear option in terms of foregone investment in infrastructure, development, social programs, or industries - may prove prohibitive for many countries. ${ }^{6}$ Second, at least in the NPT era, the pursuit of nuclear weapons is likely to be met with disapproval from influential states and international organizations. The possibility of ending up a pariah excluded from much of the international economic system, as have the DPRK and Iran, is an unattractive possibility for most states. Third, just as some parts of the state and various domestic interests may have a vested interest in pursuing nuclear weapons, others may have material or ideational reasons for opposing the nuclear option. If these forces prove more powerful, leaders who supported the nuclear option may find their position weakened. To pursue nuclear weapons successfully in spite of resource constraints and opposition from the international community, government leaders must have a high degree of confidence in their domestic support coalition.

\section{COMPARING NUCLEAR WEAPONS PROGRAMS TO MILITARY ROCKETRY PROGRAMS}

\section{NUCLEAR WEAPONS PROGRAMS}

In addition to these well-known motives and constraints to pursuing nuclear weapons, recent scholarship has emphasized supply-side technology constraints that raise the costs of attempting to pursue nuclear weapons. Acquiring nuclear weapons via indigenous effort (that is, as opposed to purchasing them - as

\footnotetext{
${ }^{5}$ For more on the supply-side challenges to nuclear weapons proliferation, see Singh and Way (2004); Jo and Gartzke (2007); Fuhrman (2009); Kroenig (2009b); Hymans (2012); Montgomery (2013).

${ }^{6}$ See Lindley and Clemency (2009) for estimates of the percent of GDP required to produce the same number of nuclear weapons in different countries.
} 
attempted by Egypt - or receiving them from allies - as attempted by Australia) requires mastery of a substantial range of technologies, industrial processes, and scientific competencies. As Alexander Montgomery writes, "A nuclear weapons program is a large-scale socio-technical system that requires a longterm investment in multiple technologies, each with its own unique hurdles to overcome" (Meyer 1984; Montgomery 2013). These hurdles include sophisticated metallurgy, chemical engineering, nuclear engineering, nuclear physics, electronic engineering, and a large capacity for producing nitric acid, electricity, and uranium milling. A solid technological and scientific infrastructure would be necessary to build, operate, and maintain relevant plants and labs. In addition, a would-be proliferator would need a substantial number of skilled technicians and craftsmen to run and maintain the infrastructure. It is not just a question of acquiring the relevant equipment, but of operating and maintaining it over a number of years, and it is in the latter where would-be proliferators often fall short (Meyer 1984; Montgomery 2013). Moreover, the challenge is greater than that posed by a sequence of discrete technological tasks; the various steps must be carefully integrated with each other, posing an organizational/managerial challenge equal to the technological challenges (Hymans 2008).

Chief among these challenges is the construction and operation of the facilities needed to produce fissile materials and to fabricate the weapons. Although the management and organizational challenges of running nuclear programs have been underemphasized in the literature, the historical record shows that they are considerable (Hymans 2008; Hymans 2012). Poorly run organizations find the challenge of constructing and operating nuclear facilities difficult, if not impossible. For example, Romanian efforts to develop nuclear infrastructure as part of their flirtation with the bomb were dysfunctional to a comic degree. Romanian officials drew upon techniques they had used for more labor-intensive economic activities, mobilizing forced laborers to build a series of CANDU nuclear power plants based on Canadian designs; a Canadian engineer located at the site described their efforts as "more appropriate to a potato harvest than to high-technology construction” (Hymans 2008, 275).

Beyond the need for competent managers, nuclear programs rely on a high degree of tacit knowledge. Tacit knowledge - knowledge that must be acquired via hands-on learning or trial and error - looms large at both the enrichment/ separation phase of nuclear weapons programs. Countries that lack indigenous, applied technical expertise in the nuclear realm will face substantial challenges in mastering the operation of uranium enrichment and plutonium separation equipment (Montgomery 2005). Tacit knowledge is also essential to building and fabricating the nuclear weapons themselves (MacKenzie and Spinardi 1995). 
Weapons designers often refer to their craft as an "art" rather than "science," and, even in a mature nuclear weapons power like the United States, it takes 5 to 10 years for new designers to become "useful" (MacKenzie and Spinardi 1995, 62). Casting fissile materials and high explosives into shapes required for missiletopping implosion devices requires not just advanced knowledge in metallurgy, manufacturing, and engineering, but also extensive hands-on experience. The AQ Khan network, for example, attempted to pass this knowledge on in writing, but without apparent success (Montgomery 2005, 178).

Creating an effective nuclear weapons program also requires creating a broad network of supporters both inside and outside of the government. According to Flank (1995, 260), "Nuclear weapons advocates need to recruit an array of allies: the security elite, the military R\&D establishment, commercial contractors or the press... These diverse communities and interests would never monolithically decide to construct nuclear weapons, with the technical processes then obediently following in the wake of the political decision. Instead, complex systems start small and build painstakingly on existing resources." Harnessing the interests and energies of diverse constituencies to support a nuclear weapons program represents a substantial practical and political challenge. Constituencies that share complementary or overlapping interests can thus be valuable allies in advocating for resources and shaping the trajectory and goals of nuclear programs.

\section{MILITARY ROCKET PROGRAMS}

The reasons why governments seek to acquire ballistic missile and nuclear weapons capabilities often overlap, as do the capacities required to succeed in those efforts (Mettler and Reiter 2013). Yet a country need not possess missile programs to obtain nuclear weapons, just as a country need not possess nuclear weapons programs to obtain ballistic missiles. Although these two weapons capabilities follow separate developmental tracks, they naturally converge at the creation of nuclear-armed long-range ballistic missiles. Even after a country has successfully conducted its first nuclear test, it can still take years to design an effective nuclear warhead small enough to be launched on ballistic missiles (Karp 1996, 179-185). The apparent ability of Pakistan to field nuclear-armed missiles rapidly potentially indicates the close cooperation between its ballistic missile and nuclear weapons programs. This suggests that both direct and indirect bridges can be built between ballistic missile and nuclear weapons programs, potentially long before a country conducts its first nuclear tests.

The international demand for missile capabilities is much larger than the demand for nuclear weapons. Most countries start investing in their military 
rocketry programs long before they ever began pursuing nuclear weapons. In part, this is because shorter range missiles and rockets have significant tactical applications. States often begin their military rocketry R\&D programs by seeking to master the development of missiles and rockets for use on the battlefield and then move on to developing the capacity to produce more sophisticated missile variants that have strategic applications. Similarities between rocket and nuclear technologies and the knowledge, skills, and capabilities required to obtain them provide a strong basis for our linkage of the two capabilities' developmental trajectories.

The factors affecting governments' ability to develop advanced civil and military rocketry capabilities have been the subject of study by historians, political scientists, and policy-planners (e.g. MacDougal 1985; MacKenzie 1990; Karp 1996; Rumsfeld Commission 1998; Mistry 2003; Gormley 2008; Early 2014). Developing indigenous ballistic missile capabilities requires countries to cultivate military rocketry research and development (R\&D) establishments that can bring together scientists, engineers, and technicians to master the technological complexities of rocketry (Karp 1996, Chapter 4). Similar to nuclear technology, rocketry technology is inherently dual-use as there is substantial overlap in the scientific basis, design, and technical aspects of civilian and military rockets. Tacit knowledge also plays a critical role in the design, construction, and operation of rockets (Karp 1996; Montgomery 2005; Johnson-Freese 2007). Designing and developing complex rockets requires a systems-level approach to integrating a variety of technologies and components, such as their engines, guidance systems, casing materials, and payloads (Gormley 2008). Just as a nuclear weapons program requires the ability to integrate a range of technologies and operations effectively, so do rocketry programs. Building rockets also requires a skilled workforce in order to meet the exacting construction standards they require to operate successfully. Since most rockets are designed to be used only once, and the slightest malfunctions, miscalculations, and accidents often lead to failure, quality control is exceptionally important (Karp 1996). As such, successful missile and space programs require cultivating significant amounts of scientific and technical (S\&T) human capital in the rocketry realm (Early 2014).

Finally, obtaining advanced military or civilian rocket capabilities requires governments to effectively coordinate and manage organizationally complex projects that involve substantial outlays of resources. Acquiring indigenous rocket capabilities can be very costly, but these costs vary on the basis of how wisely governments spend their resources. Possessing national laboratories and research universities, weapons design and testing facilities, and an extensive 
military industrial base will help countries make more effective use of the resources they devote towards acquiring rocket capabilities. According to Karp (1996, 77-97), the quality of the developmental strategy that governments employ to obtain ballistic missiles capabilities and the quality of those projects' management also help determine the ultimate success of acquisition efforts. Developing advanced indigenous rocketry capabilities requires cooperation between countries' public and private industries, research establishments, governmental agencies, and militaries. A steep learning curve may exist in figuring out how to effectively coordinate amongst the diverse actors involved in these programs, evaluating the best developmental strategies to pursue, and determining how to appropriately fund them. There can be many failures along the way, but scientists, engineers, and policymakers can learn from them over time. States' rocketry R\&D establishments may thus not only grow larger over time, but they should also benefit from the accumulation of tacit knowledge and S\&T human capital. Early (2014) finds, for example, that the longer a country has possessed a military rocketry R\&D program, the more likely states are to succeed in developing space launch vehicles (SLVs).

\section{FROM MISSILE PROGRAMS TO NUCLEAR WEAPONS PROGRAMS}

Given the similarities of rocket and nuclear technologies and the programmatic efforts necessary to successfully acquire them, as well as the strategic and political linkages between the two programs, we argue that countries' investments in their military rocketry sectors will enhance their ability to acquire nuclear weapons. Our theory links countries' military rocketry programs to nuclear weapons programs via two causal mechanisms. First, we argue that countries' investments in military rocketry R\&D programs spur the growth of SMICs that contribute to nuclear weapons acquisition efforts. The creation of military rocketry SMICs fosters cooperative linkages between government, industry, and academia in working on national projects, provides governments with important lessons about how to design and manage complex weapons acquisition efforts, and provides an institutionalized incubator for military S\&T human capital. Secondly, the political constituencies created by military rocketry R\&D programs may use their bureaucratic leverage to advocate for the acquisition of nuclear weapons, which would, in turn, increase the resources devoted towards military rocketry programs and their importance (Flank 1995). Scientific and strategic enclaves are often noted as important drivers of nuclear 
weapons programs (Perkovich 1999; Sagan 2000), and a large-scale military rocketry program will both increase the size and enhance the prestige of the SMIC.

When countries initiate indigenous military rocketry capabilities, they are investing in developing their S\&T human capital. Both rocketry and nuclear weapons programs require a synthesis of different disciplines (such as, physics, metallurgy, and chemistry), forcing scientists, engineers, and technicians to work together. Countries are more apt to initiate military R\&D efforts on rocket technology as opposed to nuclear weapons technology because missile technology has immediate tactical applications, the technological challenges to mastering basic rocketry are lower, and rocket programs do not require rare materials (like uranium) to initiate. By funding these research programs, governments are injecting money into the training of scientists, engineers, and skilled technicians and their employment in SMICs, and in acquiring the management capacity to run large-scale programs successfully.

In addition to human capital, governments that seek to develop advanced military rocketry capabilities require significant private or public sector investments in research infrastructure that can lay the foundation for nuclear weapons programs. Advanced research on new materials, fuels, chemicals, and electronic systems requires the use of laboratories or research facilities. The fabrication of rockets and missiles requires large-scale manufacturing facilities, as well as access to a varied collection of high-quality precursor components and raw materials from which the rockets will be built. Whereas some countries possess completely government-run arms industries, other countries' arms industries mix public and private ventures. Mature rocketry R\&D programs can build up either sector in ways that would be subsequently beneficial to nuclear weapons R\&D efforts. Lastly, testing rockets and ballistic missiles require large, remotely located test facilities. Governments seeking to test nuclear weapons often confront similar dilemmas in finding areas in which to conduct their tests. The investments governments make in funding weapons laboratories, supporting governmental or private sector arms manufacturing programs, and developing and building weapons test facilities can all pay significant dividends for nuclear weapons programs as well. To be sure, not all of the infrastructure nor industries military rocketry R\&D programs spawn will be directly applicable to a nuclear weapons program, but governments need not start from scratch in creating the necessary $R \& D$ infrastructure for nuclear weapons programs if they already possess a mature military rocketry SMIC.

Mature military rocketry SMICs can also yield valuable organizational benefits for governments pursuing large-scale rocketry R\&D projects. Military 
rocketry programs require actors from government bureaucracies, academia and research institutions, militaries, and the private sector to work together towards the achievement of joint goals. Organizationally, creating synergistic ties between actors from these institutions and finding ways of facilitating productive working relationships between them is one of the most difficult challenges associated with developing advanced rocketry capabilities (Karp 1996). Similar challenges confront governments pursuing nuclear weapons (Hymans 2012; Montgomery 2013). The choices that governments make in organizing their rocketry programs help determine whether their efforts succeed or fail and how much such efforts ultimately cost (Karp 1996). To the extent that governments can learn from successes and failures with their rocketry programs, their management of their nuclear weapons programs will be improved. Thus, governments can benefit from the institutional connections and programmatic knowledge they have previously obtained from their military rocketry programs and apply that towards their pursuit of nuclear weapons capabilities-thus lowering the costs of pursuing nuclear weapons, making their efforts more likely to succeed, and decreasing the time it takes to succeed.

In the DPRK, for example, the government's investments in its ballistic missile sector appeared to pay dividends for its efforts to acquire nuclear weapons. Hymans (2012, 248-255) argues that the neo-patrimonial character of the DPRK regime played a major role in impeding its nuclear weapons and missile development efforts. Yet the DPRK still managed to develop both capabilities, emerging as one of the world's most active ballistic missile proliferators during the 1980 s and, subsequently, acquiring nuclear weapons capabilities in the 2000s (Pollack 2011). A key institutional innovation adopted by Kim Il-Sung that aided in these efforts was the founding of the Hamhŭng Military Academy in 1965, which had "the mandate... to nurture those personnel which are able to develop mid- and long-range ballistic missiles." This research and training academy, subordinate to the DPRK's Ministry of Defense, helped provide the "foundation" for the subsequent indigenous ballistic missile production capability the DPRK eventually acquired. ${ }^{8}$ The DPRK possesses a set of similarly oriented scientific-military and arms-production institutions, such as the Second Natural Science Institute and the Second Economic Committee, that house

\footnotetext{
7 The academy was subsequently relocated to Kanggye and renamed, the Kanggye Military Academy. It is also referred to as the National Defense University (Bermudez 1999, 2).

${ }^{8}$ Later on, the DPRK's Academy of Defense Sciences played a key role in helping the regime reverse-engineer and reproduce its first for-production ballistic missile system in the 1980 os (Bermudez 1999, 2-3, 10-13).
} 
both missile and nuclear weapons-related research, design, and production efforts. ${ }^{9}$ The close organizational overlap between the institutions involved in housing these highly complex, technical weapons development projects suggest that the DPRK's nuclear weapons effort could have readily benefited from lessons learned from its prior success in obtaining indigenous ballistic missile production capabilities, the R\&D infrastructure it created for those programs, and the cultivation of a skilled body of scientists and technicians in a country in which S\&T capital is scarce. The missile technology for nuclear technology exchange between the DPRK and Pakistan also illustrates the close associational linkages between the DPRK's weapons development and acquisition efforts in both sectors (Montgomery 2005). Understanding the connections between the DPRK's military rocketry R\&D programs and nuclear weapons program can help explain how it managed to acquire nuclear weapons in spite of other aspects of its regime that likely retarded the program's progress (Hymans 2008).

Lastly, the governmental bureaucracies created to manage military rocketry programs and interest groups that commercially benefit from them can grow into powerful political constituencies that could support the pursuit of nuclear technology and weapons. For example, the founder of modern French rocketry, Robert Esnault-Pelterie, was a prominent advocate of exploring the potential applications of nuclear technology for rocketry during the 1930s (Turner 2009: 219). Given that possessing nuclear weapons can create a demand for long-range ballistic missiles, which governments otherwise have few incentives to possess, actors within military rocketry SMICs have strong incentives to push politicians towards acquiring nuclear weapons. Because many of the same policy actors that have a voice with respect to governmental missile policies will also have a voice with respect to nuclear policies, a mature military rocketry SMIC can amplify the interests that many of those actors might have in acquiring nuclear weapons (Flank 1995). Thus, possessing mature military rocketry research programs will contribute to countries' capacity to acquire nuclear weapons and the political demand within governments to obtain them.

While this theoretical argument's most salient implications apply to the acquisition of nuclear weapons, it also has broader implications for which states obtain latent nuclear capabilities. A broad number of political disincentives and norms have helped limit the number of states actually acquiring nuclear weapons. Some of these factors, such as the nature of the security environment, normative context, or regime type, may moderate the relationship between

${ }^{9}$ For a more complete account of these institutions, see Mansourov (1995); Bermudez (1999); NTI (2012). 
military rocketry SMICs and the acquisition of nuclear weapons. ${ }^{10}$ After all, a far greater number of states have mastered the capabilities necessary to create nuclear weapons than have actually done so. Germany and Japan are good examples of states that could readily build nuclear weapons if they wanted to but have made a political decision not to. States are considered as having achieved latent nuclear status when they acquire the ability to produce the fissile materials required to create nuclear weapons, either in the form of uranium enrichment capabilities or plutonium reprocessing technologies, but do not possess nuclear weapons. According to data collected by Fuhrmann and Tkach (2015), 32 different countries have achieved nuclear latency at some point during their histories-roughly three times more states than have actually acquired nuclear weapons. Our theory that states' military rocketry R\&D programs have positive spillover effects in encouraging and aiding states in obtaining nuclear weaponsrelated technologies should apply to nuclear latency status as well. Our argument thus gives rise to the following two hypotheses:

Hypothesis 1a: Possession of a mature military rocketry R\&D program will decrease the time it takes for a country to acquire nuclear weapons.

Hypothesis 1b: Possession of a mature military rocketry R\&D program will decrease the time it takes for a country to achieve a latent nuclear capability.

One alternative explanation to our account is that simply possessing ballistic missile capabilities will increase their possessors' interests in acquiring nuclear weapons. Up until fairly recently, most ballistic missile systems have been quite limited in terms of accuracy (Cockburn and Cockburn 1980). Only when equipped with warheads capable of inflicting mass destruction could military planners have a reasonable degree of confidence of being able to damage the intended target of a ballistic missile. Countries possessing ballistic missiles thus have incentives to acquire nuclear weapons in order to enhance the strategic utility of their ballistic missile arsenals. Notably, this logic emphasizes only the demand that countries might have for nuclear weapons and not their ability to actually acquire them. Indeed, governments have been able to purchase shortrange ballistic missiles systems from suppliers like the Soviet Union, China, and

${ }^{10}$ We discuss these possibilities more in the conclusion. 
the DPRK for decades. ${ }^{11}$ Since they can readily be purchased, short-range ballistic missiles (SRBMs) are by far the most commonly owned type of ballistic missile. In contrast, very few states have obtained more advanced long-range ballistic missile capabilities (Gormley 2008: Chapter 2). Given the expense of developing and producing them and the even greater challenges associated with accurately targeting them, most states develop long-range ballistic missile capabilities only after they have already acquired nuclear weapons. ${ }^{12}$ As such, whether or not countries possess SRBMs represents the strongest measure for how possessing a strategic, complementary delivery capability could motivate states to acquire nuclear weapons or achieve nuclear latency status. ${ }^{13}$

Hypothesis 2a: Possession of SRBMs will decrease the time it takes for a country to acquire nuclear weapons.

Hypothesis 2b: Possession of SRBMs will decrease the time it takes for a country to achieve a latent nuclear capability.

\section{RESEARCH DESIGN}

To test our hypotheses, we conduct a quantitative analysis using data on the proliferation of nuclear weapons and the achievement of nuclear latency status in 168 countries from 1945-2007. Our unit of analysis is the country-year and our data is structured in an event history format. We include observations of countries at risk of acquiring nuclear capabilities up until the first year they actually do so, at which point they exit our data set. In our main analysis, we present the results from an event history analysis using rare events logit and a Weibull model. We employ rare events logit because it can help correct for potential bias for dependent variables in which only a small proportion of the observations involve the occurrence of the analyzed events (King and Zeng

${ }^{11}$ In contrast, long-range ballistic missile systems are almost never sold to foreign countries. China's sale of medium-range ballistic missiles to Saudi Arabia is the lone exception.

${ }^{12}$ This observation was gleaned from comparing data on long-range ballistic missile arsenals from the National Space and Ballistic Missile Data Set (Early and Fahrenkopf 2017) and updated data on nuclear weapons acquisition from Singh and Way (2004). Iran, Saudi Arabia, and the DPRK are several exceptions to this general observation. With the exception of Saudi Arabia, all countries that possess long-range ballistic missile capabilities also possess SRBM capabilities as well.

${ }^{13}$ Also, see Horowitz and Narang (2014) for their analysis of how chemical weapons and biological weapons programs can incentivize countries to pursue nuclear weapons. 
2001). The Weibull model analyzes the factors that influence the time it takes to acquire nuclear capabilities, conditional upon a country not already having done so (Box-Steffensmeier and Jones 2004). The Weibull model is also capable of producing accurate results with rare events data, ${ }^{14}$ and it has been employed in a number of previous studies of nuclear proliferation (e.g. Way and Weeks 2014; Bleek and Lorber 2014).

\section{DEPENDENT VARIABLE: NUCLEAR WEAPONS AQUISITION}

The first dependent variable of our analysis indicates the first year in which countries successfully crossed the threshold into acquiring nuclear weapons. We focus on those countries that indigenously acquired their nuclear weapons, rather than those that inherited them (e.g. Ukraine). Our method of coding identifies 10 countries that have indigenously developed nuclear weapons capacities: United States, Russia, United Kingdom, France, China, Israel, South Africa, Pakistan, India, and the DPRK. ${ }^{15}$ We code our Nuclear Weapons Acquisition variable using a one-year lead in order to avoid simultaneity bias. ${ }^{16}$

To code for states achieving nuclear latency status, we employ a binary dependent variable (Achieved Nuclear Latency) that measures when states crossed the nuclear latency threshold. Countries exit the sample once they have gained nuclear latency status or acquired nuclear weapons, but can reenter the sample if they lose those capabilities. While Fuhrmann and Tkach (2015) code 32 different states as having achieved nuclear latency, there are actually 44 different instances of countries gaining latency status in our dataset due to some countries losing and then regaining latency status. ${ }^{17}$ In order to reduce simultaneity bias, we lead Achieved Nuclear Latency by one-year. A clear advantage of using Achieved Nuclear Latency as a dependent variable is that there is substantially greater variation in the variable compared to Nuclear Weapons Acquisition. It also allows us to test our argument's more specific

${ }^{14}$ This is a reason we employ a Weibull model instead of a Cox Proportional Hazards (CHP) model, as CPH models are not as effective at analyzing rare events data.

${ }^{15}$ The nuclear weapons acquisition dates rely on updated data from Singh and Way (2004).

${ }^{16}$ We used the following dates for the other states' acquisition of nuclear weapons: Russia (1949), United Kingdom (1952), France (1960), China (1964), Israel (1968), South Africa (1979), Pakistan (1987), India (1988), and the DPRK (2006). We coded the United States' (1945) acquisition date as one year later in our data so that the observation could be used within our analysis. Including the observation does not significantly alter our findings. South Africa reentered our at-risk pool after it gave up its nuclear weapons.

${ }^{17}$ For the full set of nuclear latency dates we employ, see http://www.matthewfuhrmann.com/ uploads/2/5/8/2/25820564/nl_dataset_summary_table_.pdf. We include Spain as achieving nuclear latency from 1967-1971. 
implications for the role rocketry programs can play in facilitating the mastery of the constituent technologies associated with nuclear weapons-not just the final act of constructing and testing a weapon.

\section{INDEPENDENT VARIABLES}

To test Hypotheses $1 \mathrm{a}$ and $1 \mathrm{~b}$, we code a variable to account for the maturity of countries' military rocketry R\&D programs. Because global data is not available for the amount of money spent by countries on military rocketry programs, we focus on the age of countries' programs. This approach incorporates the notion that programs mature over time as personnel accumulate knowledge and expertise, governments learn from their experiences in selecting and managing projects, and increasingly large public and private $R \& D$ resources accumulate. It also accounts for the fact that older, more established government programs often wield more political clout. We code this variable using data from the National Space and Ballistic Missile Data Set on when governments first sponsored military rocketry R\&D efforts (see: Early 2014; Early and Fahrenkopf 2017). Our variable Rocketry R\&D constitutes a count variable of the years since initiation of a military rocketry R\&D program. Through 2009, 43 countries had initiated military rocketry R\&D programs. ${ }^{18}$ We hypothesize that the longer countries' military rocketry R\&D programs mature, the more they are capable of contributing to nuclear weapons acquisition efforts.

Although the age of countries' military rocketry R\&D programs only provides a rough approximation of the maturity of countries' rocketry-related SMICs, it offers the best available means of capturing the accumulated experience and pool of S\&T human capital that countries possess in this realm. Available evidence supports our contention that rocketry capabilities are strictly increasing in the amount of time invested in research and experimentation. For example, obtaining space launch capabilities is a comparably large and significant technical achievement in the civilian realm as obtaining nuclear weapons is in the military realm. It is therefore noteworthy that Early (2014) found that the maturity of countries' military rocketry R\&D programs - proxied by the age of the program - is positively linked to the successful acquisition of space launch capabilities. This evidence demonstrates a correlation between the length of time military rocketry programs have existed and their scope

18 For a small number of cases within the NSBM Data Set, low-end and high-end estimates were recorded for the dates when countries military rocketry R\&D efforts began. These estimates are correlated at 0.97. We employ the low-end estimates for our main analyses, but our results also hold using the high-end estimates (see the Appendix Table A8). 
and sophistication. A visual inspection of the data also shows that no country successfully acquired nuclear weapons without having a military rocketry R\&D effort. The average length of time that it took the ten nuclear weapons states to successfully acquire their weapons after they started their military rocketry R\&D efforts is approximately 22 years. At first glance, this provides circumstantial evidence that all countries that successfully acquired nuclear weapons had the opportunity to draw on synergies with their military rocketry programs and that interest groups involved in those programs could have supported efforts to obtain nuclear weapons.

To test Hypotheses 2a and 2b, we code a variable to capture whether countries possessing SRBMs are more likely to acquire nuclear weapons. We define SRBMs as ballistic missiles that have an operational range of 100 up to 1000 kilometers. SRBMs can be used in strategic as well as tactical situations, but limit their possessors to striking neighboring countries within their region unless they have naval launch platforms. Our variable SRBM Arsenal is dichotomously coded to denote whether countries possessed SRBMs in a given year or not using data from the National Space and Ballistic Missile Data Set (Early and Fahrenkopf 2017). 43 different countries possessed SRBMs at various points during their histories, and only five of the states that obtained nuclear weapons were in possession of SRBMs at the time. SRBM Arsenals and Rocketry R\&D are only correlated with one another at the 0.21 level in our sample, and they each capture distinct aspects of countries' weapons programs. Since SRBMs can be purchased from other countries (like the Soviet Union or the DPRK), SRBM Arsenals includes countries that have no indigenous military rocketry R\&D programs. Conversely, not all states that possess military rocketry programs also possess SRBMs. SRBM Arsenals and Rocketry R\&D thus test separate arguments via distinct operational measures.

We include additional variables in our analysis controlling for a range of external and internal factors that could influence the willingness and ability of states to acquire nuclear weapons. We measure for the external security environment using several different variables. To account for how a state's conflict propensity could influence its motives to acquire nuclear weapons, we code the variable International Disputes using the five-year moving average number of militarized interstate disputes. ${ }^{19}$ States' alliance relationships with nuclear powers (so-called "nuclear umbrella" relationships) are proxied by coding a count variable (Nuclear Defense Pacts) for the number of defense pacts that a country possesses with nuclear-armed states. Previous findings have

${ }^{19}$ We employed Version 4.0 of the newly updated MIDs data set (Ghosn et al. 2004). 
shown that nuclear-armed states can discourage their alliance partners from acquiring nuclear weapons (Jo and Gartzke 2007; Bleek and Lorber 2014).$^{20}$ To account for the salient nuclear weapons threats posed by the United States and the Soviet Union, we included a dichotomous variable (Super Power Rivalry) to denote whether countries had a strategic rivalry with either state. ${ }^{21}$

We employ two different control variables to account for the provision of civil and sensitive assistance that could contribute materially, technically, or via tacit knowledge to countries' nuclear weapons programs. To account for civil nuclear assistance, we employ a count variable for the number of civilian nuclear cooperative agreements (NCAs) that states have accumulated in a given year using data from Fuhrmann (2009). Using data from Kroenig (2009a), we also code a dichotomous variable to identify the period during and after when states received sensitive nuclear assistance (SNA) from a foreign country. Both variables are only coded through 2000 , though, which slightly limits their use in our analysis.

We also include a number of variables to control for the domestic political and economic characteristics of individual countries. To account for the effect of countries' governments on their likelihood of acquiring nuclear weapons, we include the standard Polity2 variable from Marshall and Jaggers (2004). This is a 21-point variable, coded from -10 (most authoritarian) to +10 (most democratic). We also include a variable to account for the effects of political transitions in countries' governments. Our variable $\Delta$ Polity2 is coded as the difference in a country's Polity2 score compared to its value from three years prior. In terms of economic factors, we include variables to control for countries' level of economic development using GDP per capita and its squared term (GDPp/c and GDPp/c Squared) using data from Gleditsch (2002). ${ }^{22}$ As a control for countries' overarching national industrial and military capabilities, we also include Singer's (1987) Composite Index of National Capability index (CINC). The variable provides a composite measure of states' military, industrial, and population-based capabilities as a proportion of the total global pool of those capabilities. Lastly, we control for temporal effects by controlling for the number of years until nuclear weapons acquisition, along with the variables squared and cubed values (Time, Time2, and Time3) as per the recommendations of Carter and Signorino (2010). Summary statistics for these variables are available in the Online Appendix.

\footnotetext{
${ }^{20}$ We employ data on defense pacts from Gibler (2009). Following Bleek and Lorber (2014), though, we code the alliance between the United States and South Korea as a defense pact.

21 We employ updated data on strategic rivalries consistent with Thompson et al. (2001).

22 We use updated figures from version 6.0 of Gleditsch's data set.
} 


\section{RESULTS}

The results of our analyses of Nuclear Weapons Acquisition that test Hypotheses 1a and 2a are displayed in Table 1. Models 1-3 display our event history analyses using the rare events logit estimator, and Models 4-6 depict our survival analysis using the Weibull model. Models 1 and 4 report the results when we only include our two main independent variables. These constrained models allow us to show the effects of our key variables prior to addressing the problem of omitted variable bias. Models 2 and 5 include a suite of additional controls, but exclude the nuclear assistance variables that only run through the year 2000. Models 3 and 6 include the full set of controls, which drops the DPRK acquisition observation from our analysis. ${ }^{23}$

The results provide strong support for our hypothesis that the length of time that states possess military rocketry R\&D programs is positively associated with their acquisition of nuclear weapons. In Models 1-3, Rocketry R\&D demonstrates positive and statistically significant effects on countries' likelihood of acquiring nuclear weapons at the $99 \%$ confidence level. The longer a country has a military rocketry R\&D program, the more likely it is to acquire nuclear weapons. Our findings indicate that these effects are robust to the inclusion of a wide range of other variables. In an average scenario using Model 3, increasing Rocketry R\&D from a value of o to the values of 10,20 , and 30 will, on average and holding all other factors constant, increase the relative risks of a country acquiring nuclear weapons in a given year by factors of 2.3, 5.6, and 13.6. In substantive terms, going from o to 30 Rocketry R\&D years shifts the baseline predicted probability from 0.003 to 0.04 . Indeed, no country that successfully acquired nuclear weapons did so without having a pre-existing military rocketry R\&D program. Past precedent thus suggests that countries without military rocketry R\&D programs are highly unlikely to acquire nuclear weapons. After a country has started such a program, these findings suggest that the likelihood of it acquiring nuclear weapons steadily grows-although not substantially in the absence of other covariates that also significantly increase the likelihood of a state going nuclear.

The results from analyses using the Weibull models (Models 4-6) indicate that Rocketry R\&D decreases the amount of time it takes for countries to acquire nuclear weapons, conditional upon their not having already obtained them. These effects are statistically significant at the 99\% level across all three

${ }^{23}$ We get the same results if we instead employ clustered standard errors. See Online Appendix 
Table 1. The Impact of Rocketry Programs and Ballistic Missiles on Nuclear Weapons Acquisition

\begin{tabular}{|c|c|c|c|c|c|c|}
\hline & Model 1 & Model 2 & Model 3 & Model 4 & Model 5 & Model 6 \\
\hline Rocketry R\&D & $\begin{array}{l}0.11^{* * *} \\
(0.02)\end{array}$ & $\begin{array}{l}0.11^{* * *} \\
(0.03)\end{array}$ & $\begin{array}{l}0.10^{* * *} \\
(0.03)\end{array}$ & $\begin{array}{l}0.04^{* *} \\
(0.02)\end{array}$ & $\begin{array}{l}0.08^{* * *} \\
(0.03)\end{array}$ & $\begin{array}{l}0.13^{* * *} \\
(0.04)\end{array}$ \\
\hline SRBM Arsenal & $\begin{array}{l}2.33^{* * *} \\
(0.71)\end{array}$ & $\begin{array}{c}1.43 \\
(1.49)\end{array}$ & $\begin{array}{c}1.48 \\
(1.90)\end{array}$ & $\begin{array}{l}1.68^{* * *} \\
(0.64)\end{array}$ & $\begin{array}{c}1.43 \\
(1.22)\end{array}$ & $\begin{array}{c}1.50 \\
(1.43)\end{array}$ \\
\hline Super Power Rivalry & & $\begin{array}{c}2.68 \\
(2.08)\end{array}$ & $\begin{array}{c}3.13 \\
(2.03)\end{array}$ & & $\begin{array}{l}5.07^{\star \star \star} \\
(1.72)\end{array}$ & $\begin{array}{l}6.18^{* \star *} \\
(1.75)\end{array}$ \\
\hline $\begin{array}{l}\text { Nuclear Defense } \\
\text { Pacts }\end{array}$ & & $\begin{array}{c}0.54 \\
(0.45)\end{array}$ & $\begin{array}{l}0.72^{* * *} \\
(0.27)\end{array}$ & & $\begin{array}{c}0.58 \\
(0.56)\end{array}$ & $\begin{array}{c}0.47 \\
(0.64)\end{array}$ \\
\hline International Disputes & & $\begin{array}{l}0.36^{* * *} \\
(0.08)\end{array}$ & $\begin{array}{l}0.26^{* *} \\
(0.10)\end{array}$ & & $\begin{array}{l}0.37^{* * *} \\
(0.13)\end{array}$ & $\begin{array}{l}0.35^{* *} \\
(0.16)\end{array}$ \\
\hline Polity2 & & $\begin{array}{c}0.09 \\
(0.09)\end{array}$ & $\begin{array}{l}0.11 \\
(0.09)\end{array}$ & & $\begin{array}{l}0.18^{*} \\
(0.10)\end{array}$ & $\begin{array}{l}0.26^{* *} \\
(0.11)\end{array}$ \\
\hline$\Delta$ Polity2 & & $\begin{array}{l}-0.20 \\
(0.16)\end{array}$ & $\begin{array}{l}-0.19 \\
(0.18)\end{array}$ & & $\begin{array}{l}-0.21 \\
(0.16)\end{array}$ & $\begin{array}{l}-0.36^{*} \\
(0.21)\end{array}$ \\
\hline GDPp/c & & $\begin{array}{c}0.00 \\
(0.00)\end{array}$ & $\begin{array}{c}0.00 \\
(0.00)\end{array}$ & & $\begin{array}{c}0.00 \\
(0.00)\end{array}$ & $\begin{array}{c}0.00 \\
(0.00)\end{array}$ \\
\hline GDPp/c Squared & & $\begin{array}{l}-0.00 \\
(0.00)\end{array}$ & $\begin{array}{l}-0.00 \\
(0.00)\end{array}$ & & $\begin{array}{l}-0.00 \\
(0.00)\end{array}$ & $\begin{array}{l}-0.00 \\
(0.00)\end{array}$ \\
\hline CINC & & $\begin{array}{l}12.46 \\
(8.32)\end{array}$ & $\begin{array}{c}7.86 \\
(7.28)\end{array}$ & & $\begin{array}{l}30.43^{\star * *} \\
(10.16)\end{array}$ & $\begin{array}{l}26.73^{\star * *} \\
(10.30)\end{array}$ \\
\hline NCAs & & & $\begin{array}{c}0.00 \\
(0.02)\end{array}$ & & & $\begin{array}{l}-0.07^{*} \\
(0.04)\end{array}$ \\
\hline SNA & & & $\begin{array}{c}0.80 \\
(1.50)\end{array}$ & & & $\begin{array}{c}0.84 \\
(1.22)\end{array}$ \\
\hline Time & $\begin{array}{c}0.03 \\
(0.13)\end{array}$ & $\begin{array}{c}0.17 \\
(0.19)\end{array}$ & $\begin{array}{l}-0.01 \\
(0.40)\end{array}$ & & & \\
\hline Time2 & $\begin{array}{l}-0.00 \\
(0.01)\end{array}$ & $\begin{array}{l}-0.00 \\
(0.01)\end{array}$ & $\begin{array}{c}0.01 \\
(0.02)\end{array}$ & & & \\
\hline Time 3 & $\begin{array}{c}0.00 \\
(0.00)\end{array}$ & $\begin{array}{c}0.00 \\
(0.00)\end{array}$ & $\begin{array}{l}-0.00 \\
(0.00)\end{array}$ & & & \\
\hline Constant & $\begin{array}{c}-7.11^{* * *} \\
(0.94)\end{array}$ & $\begin{array}{c}-10.62^{* * *} \\
(3.40)\end{array}$ & $\begin{array}{c}-10.23^{* *} \\
(4.79)\end{array}$ & $\begin{array}{c}-11.31^{* * *} \\
(1.23)\end{array}$ & $\begin{array}{c}-19.75^{\star * *} \\
(3.55)\end{array}$ & $\begin{array}{c}-22.41^{* \star *} \\
(4.33)\end{array}$ \\
\hline $\begin{array}{l}\text { Wald Test for } \\
\qquad \mathrm{H} 0: \ln (p)=0\end{array}$ & & & & $\begin{array}{c}0.11 \\
(0.29)\end{array}$ & $\begin{array}{l}0.87^{* * *} \\
(0.26)\end{array}$ & $\begin{array}{l}1.09^{* * *} \\
(0.24)\end{array}$ \\
\hline $\mathbf{N}$ & 8515 & 6847 & 5818 & 8315 & 6846 & 5817 \\
\hline
\end{tabular}

Notes: ${ }^{* *}$, and ${ }^{* * *}$ denote statistical significance at the $90 \%, 95 \%$, and $99 \%$ confidence levels respectively. The value .00 and -0.00 denotes values that are smaller than .01 or -.01 . Standard errors are reported below the coefficients in parentheses. 
models. On average and holding all other factors constant, a one-unit change in Rocketry R\&D leads to a proportional increase in the likelihood of countries acquiring nuclear weapons by a factor of 1.14. Figure 1 depicts the impact of possessing differing values of Rocketry R\&D on countries' hazard functions for acquiring nuclear weapons. The graph illustrates that the likelihood of countries' acquiring nuclear weapons, conditional upon their not already having done so, is significantly higher for those countries with more mature military rocketry programs. Countries with more mature military rocketry programs are thus capable of acquiring nuclear weapons more quickly than states with more nascent military rocketry programs.

With respect to Hypothesis 2A, our analysis reveals that SRBM Arsenal is positive and statistically significant in the constrained models but loses its statistical significance when the control variables included. If the strategic aspects of possessing ballistic missiles are what chiefly influence whether states acquire nuclear weapons, we would have expected this variable to have a stronger, more consistent impact. We find that the inclusion of the International Disputes and CINC, which are moderately correlated with SRBM Arsenals, appear to be the principal reason why SRBM Arsenals loses its statistical significance when we add in the controls. The correlations between these variables suggest that salient security concerns and possessing higher levels of material capabilities make countries more likely to possess SRBMs. These are two of the major factors that also appear to drive states to acquire nuclear weapons in our models. Yet while those factors exercise strong independent effects on Nuclear Weapons Acquisition when SRBM Arsenal is included within our analysis, SRBM Arsenal's effects wash out when they are included. Although the same factors may motivate states to acquire nuclear weapons and SRBMs, the acquisition of the latter does not increase states' likelihood of acquiring the former. The correlations between Nuclear Weapons Acquisition and SRBM Arsenal observed in Models 1 and 4 thus appear spurious in nature, leaving little supporting evidence for Hypotheses 2a. Overall, the balance of evidence suggests that states' indigenous military rocketry R\&D programs-rather than their possession of ballistic missiles-play the most important role in determining whether countries acquire nuclear weapons.

To test our findings' robustness, we employed several other means of analyzing our data. First, we tried employing alternative estimators to see if they altered our results. We reran the models using probit and a Cox Proportional Hazards model. We received identical results concerning our main hypotheses. As another robustness check, we re-ran our models while dropping each case of nuclear weapons acquisition from our analysis to see if any particular case was 
Figure 1. Hazard Function for NW Acquisition at Differing Levels of Rocketry R\&D

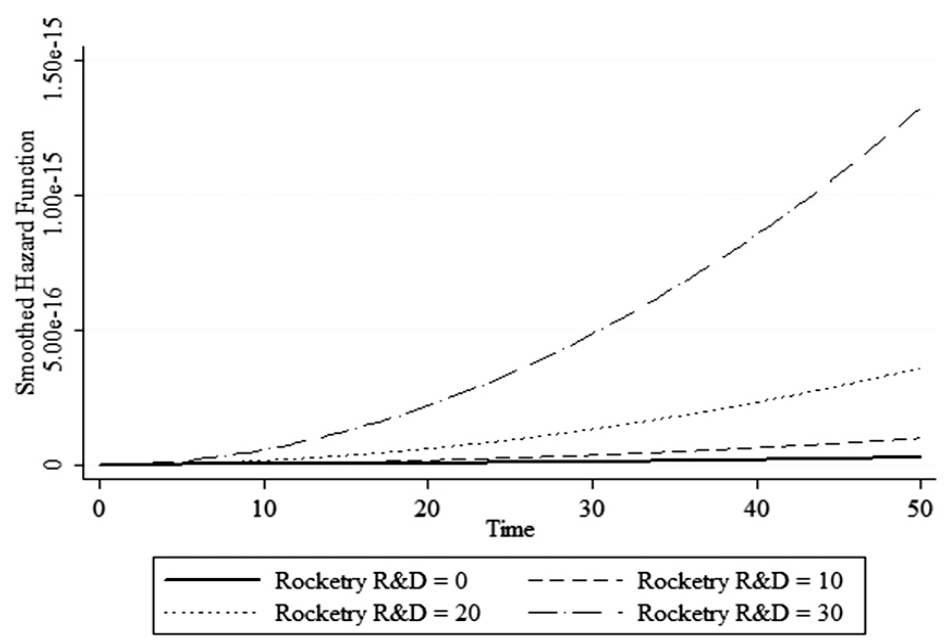

driving our results. Our results were robust to all of the exclusions except for when we removed the Pakistani case from our analysis in the event history models that included our control variables. Since Pakistan possessed a military rocketry R\&D program 25 years prior to its acquisition of nuclear weapons, it appears to be one of the higher leverage cases within our analysis. It is also possible that the creation of the Nuclear Nonproliferation Treaty may have made it less likely for states to act on spillover opportunities from rocketry programs. We added a dummy variable for the period after the NPT came into force to our analyses and found it had no effect on our variables of interest. ${ }^{24}$ Finally, we limited our sample to only those states that had a GPD per capita greater than lowest value of the variable in a state that successfully acquired nuclear weapons (China). We did this to exclude those observations in which it was highly unlikely that states could successfully acquire nuclear weapons even if they wanted to. Rocketry R\&D retained its statistical significance across all the models while SRBM Arsenal was still not significant in the unconstrained models. With respect to the control variables included in Table 1 , it is notable that International Disputes is the only other variable that produced statistically significant effects across all six models. It had a strong, positive effect on Nuclear Weapons Acquisition, which supports the security-based explanation of nuclear weapons proliferation. Overall, our findings linking the possession

${ }^{24}$ See Appendix Tables A9-A11 for the full results. 
of mature military rocketry R\&D programs to nuclear weapons acquisition are robust across a wide variety of analyses and appear to be one of the strongest determinants of whether states acquire nuclear weapons.

Turning our attention to Hypothesis $1 \mathrm{~b}$ and $2 \mathrm{~b}$, we present our models using Achieved Nuclear Latency as the dependent variable in Table 2. Across all of the models, Rocketry R\&D exercises positive and statistically significant effects on Achieved Nuclear Latency. In an average scenario using Model 9, increasing Rocketry R\&D from a value of o to the values of 10, 20, and 30 will, on average and holding all other factors constant, increase the relative risks of a country acquiring nuclear weapons in a given year by factors of 2.1, 4.4, and 9.1. Interestingly, the magnitude of Rocketry R\&D's impact on Achieved Nuclear Latency is not quite as great as its impact on Nuclear Weapons Acquisition. Its effects are still substantively significant, but military rocketry $\mathrm{R} \& \mathrm{D}$ programs appear to play the most decisive role in pushing states to acquire nuclear weapons compared to just the latent capacity to produce them. Similar to our analysis of Nuclear Weapons Acquisition, SRBM Arsenal only exercises a positive and statistically significant effect on Achieved Nuclear Latency in the constrained models. Once the effects of countries' security environment are controlled for, the effects of SRBM Arsenal on Achieved Nuclear Latency washout. These findings offer strong, consilient evidence that countries' investments in gaining mastery over rocket technology facilitate in their efforts to master the technological capabilities in the nuclear realm that could be used to produce nuclear weapons, but that simply possessing ballistic missiles does not positively influence those efforts.

Once again, it is notable that Rocketry R\&D is one of only a limited set of variables that exercised consistent effects across all of our models in Table 2. While International Disputes did have positive and statistically significant effects in the rare events analyses (Models 7-9), they washed out in the analyses that employed the Weibull Model (Models 10-12). Only the economic controls for GDPp/c and GDPp/c Squared exercised consistent effects across the models, revealing evidence of a curvilinear relationship between economic development and nuclear latency. Substantively, those findings indicate that states at the lowest and highest range of economic development are less likely to achieve nuclear latency, while those at the middle-range are most likely to do so. Taken together, our findings indicate that possessing mature military rocketry R\&D programs, rather than possessing SRBMs, is a strong contributor to the proliferation of nuclear weapons and the technological capabilities that allow them to be built. 
Table 2. The Impact of Rocketry Programs and Ballistic Missiles on Achieved Nuclear Latency

\begin{tabular}{|c|c|c|c|c|c|c|}
\hline & Model 7 & Model 8 & Model 9 & Model 10 & Model 11 & Model 12 \\
\hline \multirow[t]{2}{*}{ Rocketry R\&D } & $0.06^{* * *}$ & $0.07^{\star * *}$ & $0.07^{* * *}$ & $0.06^{* * *}$ & $0.07^{* \star *}$ & $0.07^{* *}$ \\
\hline & $(0.01)$ & $(0.01)$ & $(0.02)$ & $(0.01)$ & $(0.02)$ & $(0.03)$ \\
\hline \multirow[t]{2}{*}{ SRBM Arsenal } & $1.42^{\star \star *}$ & 0.40 & 0.09 & $1.20^{* *}$ & -0.03 & -0.61 \\
\hline & $(0.38)$ & $(0.45)$ & $(0.58)$ & $(0.53)$ & $(0.67)$ & $(0.84)$ \\
\hline \multirow[t]{2}{*}{ Super Power Rivalry } & & -1.58 & -0.35 & & -3.04 & -1.13 \\
\hline & & $(2.67)$ & $(2.67)$ & & $(4.22)$ & $(4.02)$ \\
\hline Nuclear Defense & & $0.43^{* \star *}$ & $0.44^{* *}$ & & 0.23 & 0.14 \\
\hline & & $(0.16)$ & $(0.22)$ & & $(0.29)$ & $(0.38)$ \\
\hline \multirow{2}{*}{ International Disputes } & & $0.59^{* * *}$ & $0.49^{* * *}$ & & 0.15 & 0.31 \\
\hline & & $(0.15)$ & $(0.15)$ & & $(0.25)$ & $(0.22)$ \\
\hline \multirow[t]{2}{*}{ Polity2 } & & -0.03 & -0.01 & & $-0.06^{*}$ & -0.03 \\
\hline & & $(0.03)$ & $(0.03)$ & & $(0.04)$ & $(0.04)$ \\
\hline \multirow[t]{2}{*}{$\Delta$ Polity2 } & & 0.00 & -0.01 & & 0.03 & -0.05 \\
\hline & & $(0.05)$ & $(0.05)$ & & $(0.05)$ & $(0.04)$ \\
\hline \multirow[t]{2}{*}{ GDPp/c } & & $0.00^{* * *}$ & $0.00^{\star *}$ & & $0.00^{* *}$ & $0.00^{* *}$ \\
\hline & & $(0.00)$ & $(0.00)$ & & $(0.00)$ & $(0.00)$ \\
\hline \multirow[t]{2}{*}{ GDPp/c Squared } & & $-0.00^{* * \star}$ & $-0.00^{* *}$ & & $-0.00^{* *}$ & $-0.00^{* *}$ \\
\hline & & $(0.00)$ & $(0.00)$ & & $(0.00)$ & $(0.00)$ \\
\hline \multirow[t]{2}{*}{ CINC } & & $43.00^{*}$ & 31.88 & & $80.68^{* *}$ & 48.58 \\
\hline & & (24.01) & $(24.28)$ & & $(36.07)$ & (32.18) \\
\hline \multirow[t]{2}{*}{ NCAs } & & & 0.01 & & & 0.03 \\
\hline & & & $(0.01)$ & & & $(0.02)$ \\
\hline \multirow[t]{2}{*}{ SNA } & & & $1.28^{*}$ & & & $2.26^{* \star *}$ \\
\hline & & & $(0.76)$ & & & $(0.68)$ \\
\hline \multirow[t]{2}{*}{ Time } & 0.01 & -0.09 & -0.02 & & & \\
\hline & $(0.10)$ & $(0.12)$ & $(0.15)$ & & & \\
\hline \multirow[t]{2}{*}{ Time $^{2}$} & 0.00 & 0.01 & 0.01 & & & \\
\hline & $(0.01)$ & $(0.01)$ & $(0.01)$ & & & \\
\hline \multirow[t]{2}{*}{ Time $^{3}$} & -0.00 & $-0.00^{* *}$ & -0.00 & & & \\
\hline & $(0.00)$ & $(0.00)$ & $(0.00)$ & & & \\
\hline Constant & $\begin{array}{l}-6.12^{* * *} \\
(0.60)\end{array}$ & $\begin{array}{l}-7.89^{* * *} \\
(1.03)\end{array}$ & $\begin{array}{l}-8.19^{* \star *} \\
(1.26)\end{array}$ & $\begin{array}{l}-9.93^{* * *} \\
(0.51)\end{array}$ & $\begin{array}{l}-12.12^{* * *} \\
(0.88)\end{array}$ & $\begin{array}{l}-13.26^{* * *} \\
(1.24)\end{array}$ \\
\hline Wald Test for & & & & $0.21^{* *}$ & $0.37^{\star \star \star}$ & $0.60^{* * *}$ \\
\hline$H_{0}: \ln (p)=0$ & & & & $(0.10)$ & $(0.13)$ & $(0.15)$ \\
\hline $\mathrm{N}$ & 8150 & 6316 & 5361 & 8150 & 6316 & 5361 \\
\hline
\end{tabular}

Note: ${ }^{* *}$, and ${ }^{* * *}$ denote statistical significance at the $90 \%, 95 \%$, and $99 \%$ confidence levels respectively. The value .00 and -0.00 denotes values that are smaller than .01 or -.01 . Standard errors are reported below the coefficients in parentheses. 


\section{CONCLUSION}

In this study, we have shown that states that possess mature military rocketry $R \& D$ programs are significantly more likely to acquire nuclear weapons or the latent capacity to build them. Merely possessing short-range ballistic missileshowever acquired-is not associated with an increased likelihood of acquiring nuclear weapons or nuclear latency. Although ballistic missiles and nuclear weapons have a natural affinity, only countries that invest in creating SMICs via military rocketry R\&D programs appear to be advantaged in their efforts to master nuclear weapons technologies and become more likely to acquire them. Evaluating whether countries have made significant investments in longrunning military rocketry R\&D programs is thus a powerful indicator of how likely potential proliferators are to acquire nuclear weapons or the capabilities necessary to obtain them.

Yet we argue that military rocketry R \& D programs do more than provide an early warning indicator about the seriousness of nuclear ambitions: they also can play a causal role in pushing countries along the path to proliferation via two discrete mechanisms. First, a successful rocketry program helps build up the scientific, industrial, organizational, and technological resources necessary to execute a nuclear weapons program successfully. Nuclear programs, like rocketry programs, are large-scale scientific-industrial projects requiring the successful mastery and integration of a range of difficult technical tasks. Rocketry programs provide an incubator for learning how to orchestrate and manage such projects, and develop the military scientific/technological human capital necessary for success. Second, a successful military rocketry program enlarges the potential bureaucratic/scientific constituency for nuclear weapons, endowing these actors-often identified as important drivers of nuclear weapons programs in the analysis of specific programs-with both greater resources and enhanced prestige. Thus, mature rocketry programs can alter both the supplyside and demand-side dynamics of the nuclear weapons equation. By developing their military-scientific capabilities, states can reduce the costs of pursuing nuclear weapons, easing supply-side constraints. And by strengthening the constituency for nuclear weapons, they alter the dynamics of demand for nuclear weapons in bureaucratic struggles over national security policy.

Our findings have important implications for those interested in WMD proliferation. For scholars, they reinforce the recent renewed interest in the supply-side aspects of weapons proliferation (Fuhrmann 2009; 2012; Kroenig 2009a; 2009b). We broaden the focus from nuclear technology specifically by focusing on the importance of a cognate, but distinct, set of technologies 
and capabilities. Our findings are also relevant to the recent literature on the diffusion of military technology (Horowitz 2010; Fuhrmann and Horowitz 2017). They illustrate how the development of expertise in one technology (military rocketry) can spill over to another (nuclear weapons), but also reveal that the mere spread of missiles themselves (without an indigenous reservoir of expertise) does not have these spill-over effects. Our study presents several avenues for future research. While our analysis reveals that mature military rocketry R\&D programs contribute both to states' achieving nuclear latency and nuclear weapons, further research could explore why only some states go on to acquire nuclear weapons. A security motive or normative factor, for example, could be interacting with the possession of military rocketry R\&D programs in influencing states' decision to remain latent nuclear powers versus building nuclear weapons. For example, the existence or emergence of an alliance with a nuclear-armed power could attenuate the effect of a rocketry program in creating momentum towards nuclear weapons. Alternatively, regime type may mediate the effects of rocketry SMICs by shaping the autonomy and influence of scientific and military establishments or the organizational strategies of the state in managing these types of projects. Another potential extension of our project could be to examine the effects that ballistic missiles and military rocketry programs have on states' pursuit and acquisition of chemical and biological weapons.

For policy-makers, our findings have several important implications. One is that significant investment in military rocketry programs provides a useful indicator of the seriousness of (possible) nuclear ambitions. Every country that has successfully acquired nuclear weapons has had an ongoing military rocketry R\&D program. Such programs are the strongest indicators that countries are at a higher risk of acquiring nuclear weapons. Importantly, simply possessing ballistic missiles is not a strong early warning indicator. In the past, acquisition of "off the shelf" missiles has often been greeted with great concern. For example, Saudi Arabia's purchase of CSS-2 missiles from China in the 1980s generated much concern within the non-proliferation community. Our analysis suggests that such concerns can be easily over-stated and that significant investments in military rocketry R \& D programs, such as that by Syria starting in 1970, should be taken much more seriously than the purchase of missiles. Digging a bit deeper, we can also speculate that monitoring the relative success of rocketry programs can provide an important indicator. In a sense, rocketry programs are like a trial run of a country's ability to execute complicated, challenging projects similar to nuclear weapons programs. A country unable to master rocketry technology may prove unlikely to move on to nuclear weapons, or at least unable 
to do so successfully. Success, however, demonstrates sufficient organizational capacity to proceed to other, perhaps even more challenging tasks such as developing and fielding nuclear weapons.

Our findings also shed light into understanding both the pathway that the DPRK took in acquiring nuclear weapons and its potential contributions to nuclear weapons proliferation. While the DPRK does not have a broad scientific and industrial base, it made focused investments in the missile and nuclear realms. The DPRK's investments in building up its military rocketry program appeared to pay dividends in its subsequent efforts to acquire nuclear weapons. Our theory suggests that the DPRK's approach could be replicated by other less-developed countries that are willing to make targeted investments in their missile and nuclear programs. Our findings also contextualize the risks posed by the DPRK's involvement in the proliferation of ballistic missiles. Our findings suggest that the DPRK's sale of "off-the-shelf" SRBMs is unlikely to contribute to its customers' nuclear proliferation. However, the DPRK's more recent approach of engaging in collaborative missile development projects with countries like Syria and Iran (Pollack 2011) pose a much greater risk according to our theory. Since these arrangements contribute to the development of recipient countries' scientific and technical communities, such assistance is far more dangerous from a nuclear proliferation perspective. Indeed, the revelations that the DPRK was also providing Syria with clandestine assistance in the construction of the secret nuclear facility at Al-Kibar (FAS 2008: 5; IAEA 2011) suggest that the DPRK is willing to package both missile- and nuclear-related assistance together. Ballistic missile assistance provided by the DPRK could be particularly dangerous, because it has already learned how to maximize leveraging its missile programs on behalf of its nuclear weapons programs.

\section{REFERENCES}

Allison, Graham. 1971. Essence of Decision: Explaining the Cuban Missile Crisis. Boston: Little, Brown, \& Co.

Bennett, Scott. 1998. "Integrating and Testing Models of Rivalry Duration." American Journal of Political Science 42(4), 1200-1232.

Bermudez, Joseph. 1999. "A History of Ballistic Missile Development in the DPRK.” Monitoring Proliferation Threats Project, Occasion Paper \#2. Monterey: Monterey Institution, Center for Nonproliferation Studies.

Betts, Richard. 1993. "Paranoids, Pygmies, Pariahs and Nonproliferation Revisited.” In Z. S Davis and B. Frankel ed., The Proliferation Puzzle: 
Why Nuclear Weapons Spread (and What Results). Portland: Frank Cass \& Company.

Bleek, Philip and Eric Lorber. 2014. "Security Guarantees and Allied Nuclear Proliferation." Journal of Conflict Resolution 58(3), 429-454.

Box-Steffensmeier, Jan and Bradford Jones. 2004. Event History Modeling. New York: Cambridge University Press.

Carter, David and Curtis Signorino. 2010. "Back to the Future: Modeling Time Dependence in Binary Data." Political Analysis 18(3), 271-292.

Cockburn, Andrew and Alexander Cockburn. 1980. "The Myth of Missile Accuracy." New York Review of Books (20 November). Accessed at http://www.nybooks.com/articles/archives/1980/nov/20/the-mythof-missile-accuracy/ (September 1, 2017).

Early, Bryan. 2014. "Exploring the Final Frontier: An Empirical Analysis of Civil Space Proliferation." International Studies Quarterly 58(1), 55-67.

Early, Bryan and Nolan Fahrenkopf. 2017. "Shooting for the Stars: Introducing the National Space and Ballistic Missile (NSBM) Dataset." SSRN eLibrary. Accessed at https://ssrn.com/abstract=3001913 (September 1, 2017).

Flank, Steven. 1993. "Exploding the Black Box: The Historical Sociology of Nuclear Proliferation.” Security Studies 3(2), 259-294.

Freedman, Lawrence. 1994. "Great Powers, Vital Interests and Nuclear Weapons." Survival 36, 35-52.

Federation of American Scientists (FAS). 2008. "Background Briefing with Senior U.S. Officials on Syria's Covert Nuclear Reactor and North Korea's Involvement." Accessed at http://www.fas.org/irp/ news/2008/04/odnio42408.pdf (September 1, 2017).

Fuhrmann, Matthew. 2009. "Spreading Temptation: Proliferation and Peaceful Nuclear Cooperation Agreements." International Security 34(1), 7-41. . 2012. Atomic Assistance: How "Atoms for Peace” Programs Cause Nuclear Insecurity. Ithaca: Cornell University Press.

Fuhrmann, Matthew and Horowitz Michael. 2017. "Droning On: Explaining the Proliferation of Unmanned Aerial Vehicles." International Organization 71(2), 397-418.

Fuhrmann, Matthew and Benjamin Tkach. 2015. "Almost Nuclear: Introducing the Nuclear Latency Dataset." Conflict Management \& Peace Science 32(4), 443-461.

Gartzke, Erik, Jeffrey Kaplow, and Rupal Mehta. 2014. "The Determinants of Nuclear Force Structure.” Journal of Conflict Resolution 58(3), 481-508. 
Gibler, Douglas M. 2009. International Military Alliances, 1648-2008. Washington, D.C.: CQ Press.

Ghosn, Faten, Glenn Palmer, and Stuart Bremer. 2004. "The MID3 Data Set, 1993-2001: Procedures, Coding Rules, and Description." Conflict Management and Peace Science 21, 133-154.

Gleditsch, Kristian. 2002. "Expanded Trade and GDP Data" Journal of Conflict Resolution 46, 712-724.

Gormely, Dennis. 2008. Missile Contagion: Cruise Missile Proliferation and the Threat to International Security. Santa Barbara, California: Praeger Security International.

Halperin, Morton. 1974. Bureaucratic Politics and Foreign Policy. Washington D.C.: Brookings Institution.

Horowitz, Michael. 2010. The Diffusion of Military Power: Causes and Consequences for International Politics. Princeton, New Jersey: Princeton University Press.

Horowitz, Michael and Neil Narang. 2014. "Poor Man's Atomic Bomb? Exploring the Relationship between 'Weapons of Mass Destruction." Journal of Conflict Resolution 58(3), 509-535.

Hymans, Jacques E.C. 2008. "Assessing North Korean Nuclear Intentions and Capacities: A New Approach.” Journal of East Asian Studies 8(2), 259292.

Hymans, Jacques E. C. 2012. Achieving Nuclear Ambitions: Scientists, Politicians, and Proliferation. New York: Cambridge University Press.

International Atomic Energy Agency (IAEA). 2011. Implementation of the NPT Safeguards Agreement in the Syrian Arab Republic, GOV/2011/30. Vienna: IAEA.

Jo, Dong-Joon and Erik Gartzke. 2007. "Determinants of Nuclear Weapons Proliferation." Journal of Conflict Resolution 51(1), 167-194.

Johnson-Freese, Joan. 2007. Space as a Strategic Asset. New York: Columbia University Press.

Karp, Aaron. 1996. Ballistic Missile Proliferation: The Politics and Technics. Oxford: Oxford University Press.

King, Gary and Langche Zeng. 2001. "Explaining Rare Events in International Relations.” International Organization 55(3), 693-715.

Kroenig, Matthew. 2009a. "Exporting the Bomb: Sensitive Nuclear Assistance and Proliferation." American Political Science Review 103(1), 113-133. . 2009b. "Importing the Bomb: Sensitive Nuclear Assistance and Nuclear Proliferation." Journal of Conflict Resolution 53(2), 161-180.

Lindley, Dan, and Kevin Clemency. 2009. "Low-Cost Nuclear Arms Races." 
Bulletin of the Atomic Scientists 65(2) (March 1), 44-51.

McDougall, Walter. 1985. The Heavens and the Earth: A Political History of the Space Age. New York: Basic Books.

MacKenzie, Donald. 1990. Inventing Accuracy: A Historical Sociology of Nuclear Missile Guidance. Cambridge: MIT Press.

MacKenzie, Donald, and Graham Spinardi. 1995. "Tacit Knowledge, Weapons Design, and the Uninvention of Nuclear Weapons." American Journal of Sociology 101(1), 44-99.

Marshall, Monty G. and Keith Jaggers. 2009. Polity IV Project: Political Regime Characteristics and Transitions, 180o-2008.

Mettler, Simon and Dan Reiter. 2013. "Ballistic Missiles and International Conflict." Journal of Conflict Resolution 57(October), 854-880.

Meyer, Stephen. 1984. The Dynamics of Nuclear Proliferation. Chicago: University of Chicago Press.

Mistry, Dinshaw. 2003. Containing Missile Proliferation. Seattle: University of Washington Press.

Mansourov, Alexandre. 1995. "The Origins, Evolution, and current Politics of the North Korean Nuclear Program." Nonproliferation Review 2(3), 25-38.

Montgomery, Alexander. 2005. "Ringing in Proliferation: How to Dismantle an Atomic Bomb Network." International Security 30(2), 153-187. 2013. "Stop Helping Me: When Nuclear Assistance Impedes Nuclear Programs." In Adam Stulberg and Matthew Fuhrmann eds., The Nuclear Renaissance and International Security, Stanford: Stanford University Press.

National Intelligence Council. 2000. "Global Trends 2015: A Dialogue about the Future with Nongovernment Experts." NIC 200O-O2.

Nuclear Threat Initiative (NTI). 2012. "North Korea: Facilities." Country Profiles. Accessed at http://www.nti.org/country-profiles/north-korea/ facilities/ (December 31, 2012).

O’Neill, Barry. 2006. "Nuclear Weapons and National Prestige." SSRN eLibrary. Accessed at http://papers.ssrn.com/sol3/papers. cfm?abstract_id=887333 (September 1, 2017).

Perkovich, G. 1999. India's Nuclear Bomb: The Impact on Global Proliferation. Berkeley: University of California Press.

Pollack, Joshua. 2011. "Ballistic Trajectory: The Evolution of North Korea's Ballistic Missile Market." Nonproliferation Review 18(2), 411-429.

Rumsfeld Commission. 1988. Report of the Commission to Assess the Ballistic Missile Threat to the United States. Washington, D.C.: 104th Congress of the United States. 
Sagan, Scott D. 1996/1997. "Why Do States Build Nuclear Weapons?: Three Models in Search of a Bomb." International Security 21(3), 54-86. . 2000. "Rethinking the Causes of Nuclear Proliferation: Three Models in Search of a Bomb?". In V.A. Utgoff eds., The Coming Crisis: Nuclear Proliferation, U.S. Interests, and World Order. Cambridge, Massachusetts: MIT Press, 17-50.

Schelling, Thomas. 1966. Arms and Influence. New Haven: Yale University Press.

Singh, Sonali and Christopher Way. 2004. "The Correlates of Nuclear Proliferation: A Quantitative Test." Journal of Conflict Resolution 48(6), 859-885.

Singer, J. David. 1987. "Reconstructing the Correlates of War Dataset on Material Capabilities of States, 1816-1985." International Interactions 14, 115-132.

Solingen, Etel. 2007. Nuclear Logics: Contrasting Paths in East Asia \& the Middle East. Princeton, NJ: Princeton University Press.

Thompson, William. 2001. "Identifying Rivals and Rivalries in World Politics." International Studies Quarterly 45(4), 557-586.

Turner, Martin. 2009. Rocket and Spacecraft Propulsion: Principles, Practice, and New Developments, 3rd Edition. Chichester, UK: Praxis.

Way, Christopher and Jessica Weeks. 2014. "Making it Personal: Regime Type and Nuclear Proliferation." American Journal of Political Science 58(3), 705-719. 
